\title{
El nuevo Museo Arqueológico Nacional, un museo abierto
}

\author{
Juan Pablo Rodríguez Frade | Frade Arquitectos \\ URL de la contribución <www.iaph.es/revistaph/index.php/revistaph/article/view/3595>
}

\section{RESUMEN}

En 2007 Frade Arquitectos resulta adjudicatario del concurso público que tenía como objeto la remodelación del Museo Arqueológico Nacional (MAN). La renovación integral del MAN se realizó durante los años 2008-2012 con un proyecto que pretendía responder a una necesidad de actualización y modernización, al margen de otros aspectos puramente técnicos de adecuación a la normativa vigente o relativos a los esfuerzos estructurales para soportar piezas de gran peso.

Pero, ¿cómo compaginar el respeto hacia el edifico con las exigencias necesarias de un museo? Ésta era una de las claves de la rehabilitación, llegar a un equilibrio entre la "tradición" y el "desarrollo". Asumir determinados sacrificios de planteamiento para potenciar la relación entre el edificio y la colección ha sido decisivo para alcanzar una solución que, respetuosa hacia el proyecto original, responde tanto a la demanda social de nuevos servicios de atención al público como a las nuevas necesidades museológicas y museográficas.

\section{Palabras clave}

Madrid (España) | Museo Arqueológico Nacional | Museografía | Museología | Rehabilitación arquitectónica | 


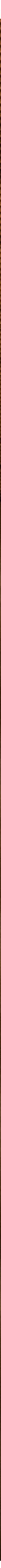




\section{EL EDIFICIO}

Como señala la placa de bronce instalada en la entrada al propio museo, el Palacio de Bibliotecas y Museos fue edificado sobre el solar que ocupaba el antiguo convento de los Agustinos Recoletos, siendo la realización arquitectónica más ambiciosa del reinado de Isabel II.

Su estilo clasicista es el habitual de otras construcciones institucionales de la época, como el Congreso de los Diputados; sin embargo su estructura es ejemplo pionero del uso generalizado del hierro en la arquitectura madrileña. La rigurosa organización de la planta rectangular con cuatro patios tiene antecedentes tanto en modelos clasicistas franceses como en los hospitales renacentistas españoles.

El Museo Arqueológico Nacional nace en 1867, mediante Real Decreto de Isabel II fechado el 20 de marzo de ese año, de forma que con su creación, España se une a la corriente extendida por una Europa que aplaude la creación por parte de los gobiernos de este modelo de museos donde albergar piezas que muestren al mundo la grandeza de la nación reforzando, a su vez, la identidad del Estado.

Ya desde su nacimiento se define el tipo de piezas que la institución debe custodiar y se determina que sus primeros fondos provengan de las colecciones pertenecientes a la monarquía española. Así, las colecciones numismáticas, arqueológicas, etnográficas, y de artes decorativas de Austrias y Borbones, pasarán a engrosar los fondos del nuevo museo, junto con las adquisiciones por parte del Estado de colecciones particulares y de las piezas recibidas de los museos provinciales.

Proyecto de Biblioteca y Museos Nacionales. Francisco Jareño, ca. 1866

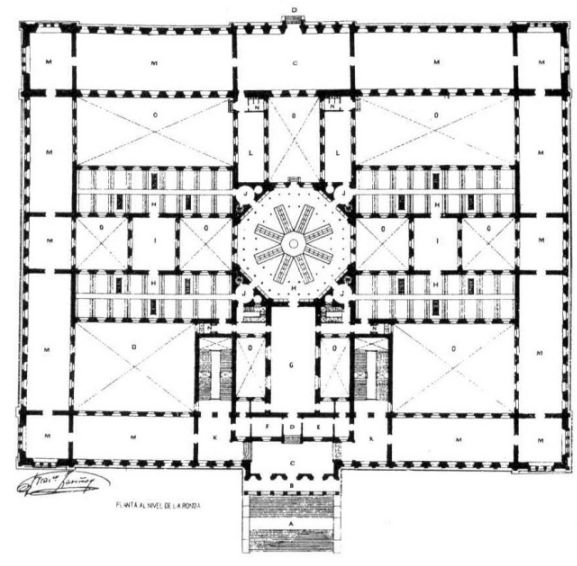

No es de extrañar que se decidiera hacer un edificio expresamente dedicado a tal fin, aunque compartido, ya desde su concepción, con la Biblioteca Nacional. Una especie de templo del saber muy en consonancia con el espíritu de la época, como de forma muy expresiva se manifiesta en los primeros dibujos de la planta del edificio. Una planta cuadrada que alberga en su exterior las colecciones del museo y que protege del ruido y de la luz la planta en forma de cruz que serviría de biblioteca. Un planteamiento funcional que refleja una idea de partida de cómo los bienes materiales deben proteger las ideas de donde proceden; la cultura material protegiendo el mundo inmaterial de las ideas materializadas en los libros y publicaciones.

Provisionalmente, el museo se instaló en un palacete conocido como el Casino de la Reina por haber pertenecido a Isabel de Braganza, esposa de Fernando VII, hasta que en 1895 sus fondos, que por entonces ya habían aumentado considerablemente, se trasladaron al actual emplazamiento en la calle Serrano, en donde un año después se instalaría también la Biblioteca Nacional. 
El edificio, que recibió desde sus inicios el nombre de Palacio de Bibliotecas y Museos, se construyó siguiendo el proyecto de los arquitectos Francisco Jareño y Alarcón y Antonio Ruiz de Salces.

De estilo neoclasicista, con claras influencias de la obra del arquitecto alemán Karl Friedrich Schinkel, cuya obra pudo conocer Jareño en sus viajes por Alemania, presenta la habitual planta cuadrada con cuatro patios simétricos. Al exterior, destacan las dos fachadas de las calles Serrano y Recoletos, correspondientes al acceso al museo y la biblioteca respectivamente. La del museo con un carácter más sobrio y arquitectónico, y la de la biblioteca más significada gracias a la gran escalinata y a su destacado programa escultórico. En 1886 Antonio Ruiz de Salces se hace cargo de las obras, finalizando su construcción en 1892, el mismo año en que moriría Jareño.

En 1983 fue declarado Bien de Interés Cultural.

\section{LOS ANTECEDENTES}

Muchas han sido las intervenciones de todo tipo que se han realizado sobre el edificio con respecto a los primeros planteamientos arquitectónicos del arquitecto Jareño sin haber perdido el inmueble ninguna de sus cualidades intrínsecas, pero no es hasta los años 70 del siglo XX cuando bajo la dirección del arqueólogo Martín Almagro, los arquitectos Luis Moya y Antonio Almagro realizan la única remodelación de carácter integral del museo en cuanto a su estructura arquitectónica e implantación museográfica. Una intervención realista y racional basada en un profundo conocimiento del edifico y en una clara visión de los objetivos a conseguir.

Es por esto que la reciente renovación integral que se ha realizado durante los años 2008-2012 ha resultado una ocasión única para actualizar y modernizar la institución, respondiendo a la demanda social de nuevos servicios de atención al público y a las nuevas necesidades museológicas y museográficas.

Aparece por tanto un problema ya habitual en cuanto a la rehabilitación de edificios de carácter histórico: ¿cómo compaginar el respeto hacia el edifico con las exigencias necesarias de un museo? A mi juicio el acierto de la intervención radica siempre en el acuerdo equilibrado entre ambos aspectos; esto es: entre "tradición" y "desarrollo"; asumiendo determinados sacrificios de planteamiento con el objeto de potenciar la relación entre el edificio y la colección, sin desmerecer ninguno de sus valores.

En 2007 Frade Arquitectos resulta adjudicatario, junto con la ingeniería Prointec S. A., del concurso público que tenía como objeto la remodelación 
integral del museo y con el que se pretendía, no sólo recuperar el esplendor que había perdido, si no también actualizarlo y hacerlo partícipe de los cambios que habían tenido lugar en una sociedad que demanda ahora otro tipo de museos, más allá de los rígidos modelos heredados del siglo XIX.

No es nuevo apuntar que el uso como museo en un edificio de carácter histórico implica una serie de sacrificios: hacia el propio edifico y hacia las respuestas que debe ofrecer desde un punto de vista funcional. Si esta premisa es contemplada desde los primeros planteamientos se puede obtener gran provecho para el conjunto, a pesar de que puede parecer a priori un inconveniente. El uso como museo para un edificio histórico resulta tremendamente agresivo pues sus instalaciones y prestaciones resultan la suma de muy diferentes tipologías arquitectónicas al tener que responder a necesidades de uso muy dispares: recorridos abiertos al visitante, piezas a custodiar de gran valor, medidas estrictas de temperatura y humedad, necesidad de generar emoción en el visitante, y al mismo tiempo ofrecer una interpretación rigurosa de las colecciones, etc.

En la rehabilitación del MAN se considera como punto de partida el mantener la estructura original del edificio primitivo, como elemento integrador del conjunto, desde una propuesta arquitectónica actual, sin que el visitante perciba el esfuerzo realizado bajo sus pies.

No deberíamos caer en visiones nostálgicas del pasado desde donde habitualmente se exageran virtudes (muchas veces de tipo romántico), olvidando aquellos aspectos negativos que conocemos existían. Es necesario poten-

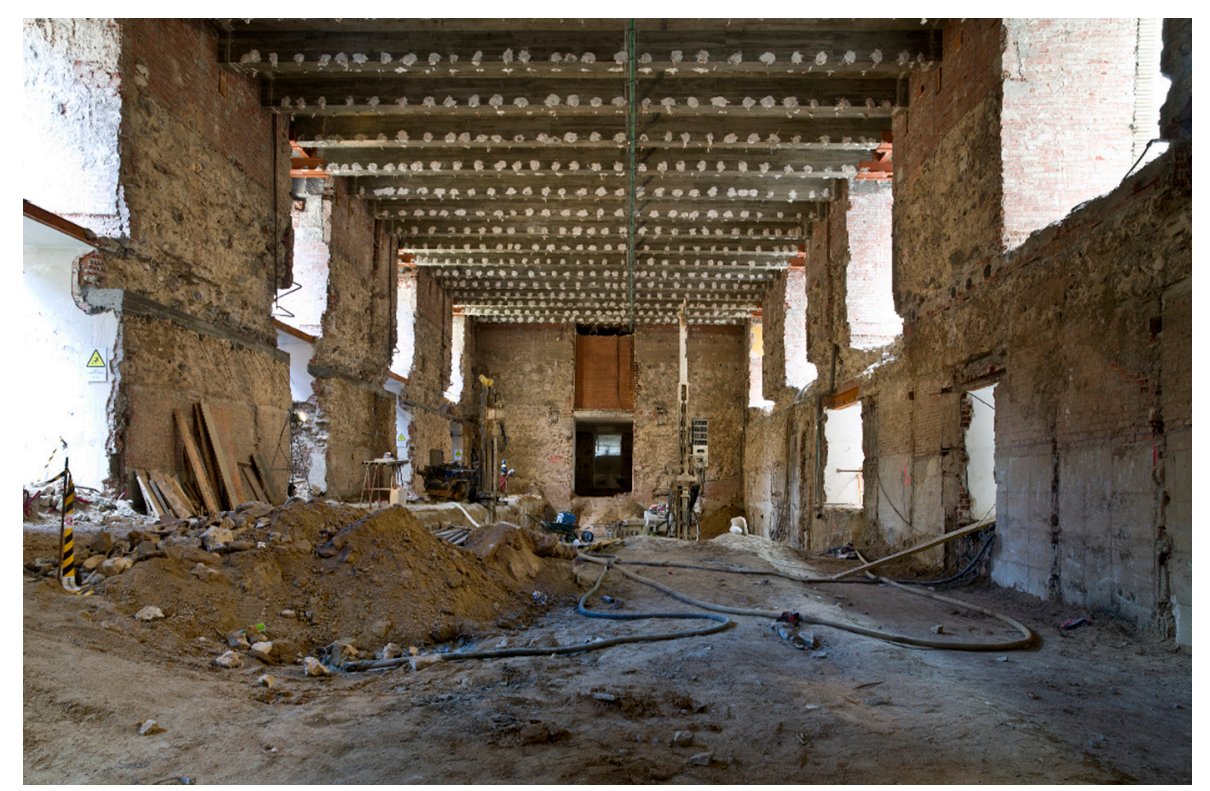


ciar los valores arquitectónicos por los que el edifico tiene interés, y que, de una u otra manera, derivan en aquello tan cierto pero tan intangible como es el "carácter" de los edificios y que no deja de ser ese conjunto de relaciones espaciales y arquitectónicas de difícil análisis racional existentes entre las diferentes estancias y en su relación con el exterior. De manera que la propuesta debería devolver aquellos valores que han ido despareciendo a lo largo de las intervenciones realizadas en los últimos años, y que consideramos fundamentales en los principios arquitectónicos e históricos del edifico de Jareño.

Es obligado solapar en la intervención la emoción que nos transmiten los museos de principios de siglo, con la eficacia comunicativa y los requerimientos de conservación que permite la tecnología actual. Pensamos que es absolutamente posible y necesario el recuperar muchos aspectos museográficos hoy aparentemente fuera de lugar pero de gran interés si son interpretados desde una clave contemporánea.

En definitiva, se trata de alcanzar una solución que emocione y sugiera en silencio, desde un planteamiento respetuoso hacia el proyecto original. Un museo más simbólico que figurativo que pueda recorrerse con emoción a través de salas con un empaque arquitectónico relevante y claramente intencionado.

\section{EL PROYECTO}

Al margen de aspectos puramente técnicos de adecuación a la normativa vigente y los relativos a los refuerzos estructurales para soportar piezas de gran peso, las intervenciones más relevantes se refieren a la creación de un nuevo espacio de acogida, la recuperación de los patios como elementos vertebradores del museo y la adecuación de los más de $2.000 \mathrm{~m}^{2}$ útiles de bajo cubierta.

Consideramos que la intervención debe hacer justicia al edificio original, recuperando algunos de sus valores perdidos y potenciando la nobleza de su arquitectura, realizando una labor de limpieza de intervenciones anteriores sin relevancia, y aportando puntuales aportaciones claramente contemporáneas.

No se trata de realizar una intervención basada en gratuitos excesos estilísticos. Hemos apostado, por el contrario, por un proyecto silencioso y sensato que solucione los problemas existentes y ponga en valor el museo y sus colecciones sin restar protagonismo a los valores implícitos del edificio, pero sin caer en interpretaciones historicistas. La única manera de salvaguardar los valores de un edificio histórico en uso parte de la constante adecuación del mismo a las nuevas necesidades. 
Así, la primera novedad es el nuevo acceso creado para propiciar la existencia de un espacio de acogida acorde con las nuevas necesidades, paliando el grave problema del museo que, hasta este momento, se mostraba cautivo de la geometría y de las características históricas y arquitectónicas del acceso principal. Era necesario dotarlo de un espacio de acogida amplio, que facilitara la orientación y uso de un lugar que respondiera a largo plazo a las necesidades existentes, y que pudiera ser utilizado en horarios a "museo cerrado" de manera simultánea y paralela a la actividad propia del edificio, pasando a formar parte de la oferta cultural de la ciudad de Madrid.

Consideramos que abordar los problemas expuestos mediante aparatosos artefactos mecánicos o tendidas rampas que salvaran el desnivel existente manteniendo la portada principal como acceso de visitantes solo solucionaría parcialmente la problemática, alterando, sin embargo, enormemente los valores arquitectónicos de uno de los elementos más nobles y destacados del edificio, y trasladando el problema al zaguán principal y a la escalinata histórica ya que, una vez en el interior del zaguán principal, de nuevo aparecen peldaños en sus tres laterales, lo cual implicaría nuevas intervenciones que afectarían al carácter histórico del núcleo central del edifico.

Dado que la planta semisótano prácticamente se encuentra a nivel del jardín exterior en la zona sur del edificio, ¿por qué no utilizar esa planta como acceso habitual de visitantes y reservar el espacio central de la planta baja como posible acceso a oficinas, biblioteca y visitas ocasionales, permitiendo así que el zaguán principal pueda ser contemplado y utilizado desde el interior del museo pero sin hacerlo de paso obligado?

Esta solución permite, además, el utilizar las plantas nobles para los usos más relevantes del museo como son las salas de exposición permanente, y ubicar los usos secundarios y de apoyo en las plantas de menor importancia.

De esta manera se formaliza un gran salón de acogida, en donde se difumina la frontera entre espacio urbano y espacio público interior, pues los usos que se disponen en esa zona bien podrían encontrarse en el exterior del edificio. Así, la ciudad se incorpora al interior del museo, y éste se abre a la ciudad de forma amable y acogedora sin generar barreras de ningún tipo. Un espacio de transición entre la calle y el museo óptimo para la celebración de actividades y manifestaciones artísticas, y adecuado para albergar los diferentes servicios de atención al visitante. Un lugar para el que no es necesario adquirir entrada ni acreditación. Una zona de carácter urbano en una de las calles más transitadas de Madrid.

Por otro lado se recupera el forjado de planta baja en una cota próxima a la que tuvo a principios de siglo, sobre los antiguos patios árabe y romano, 

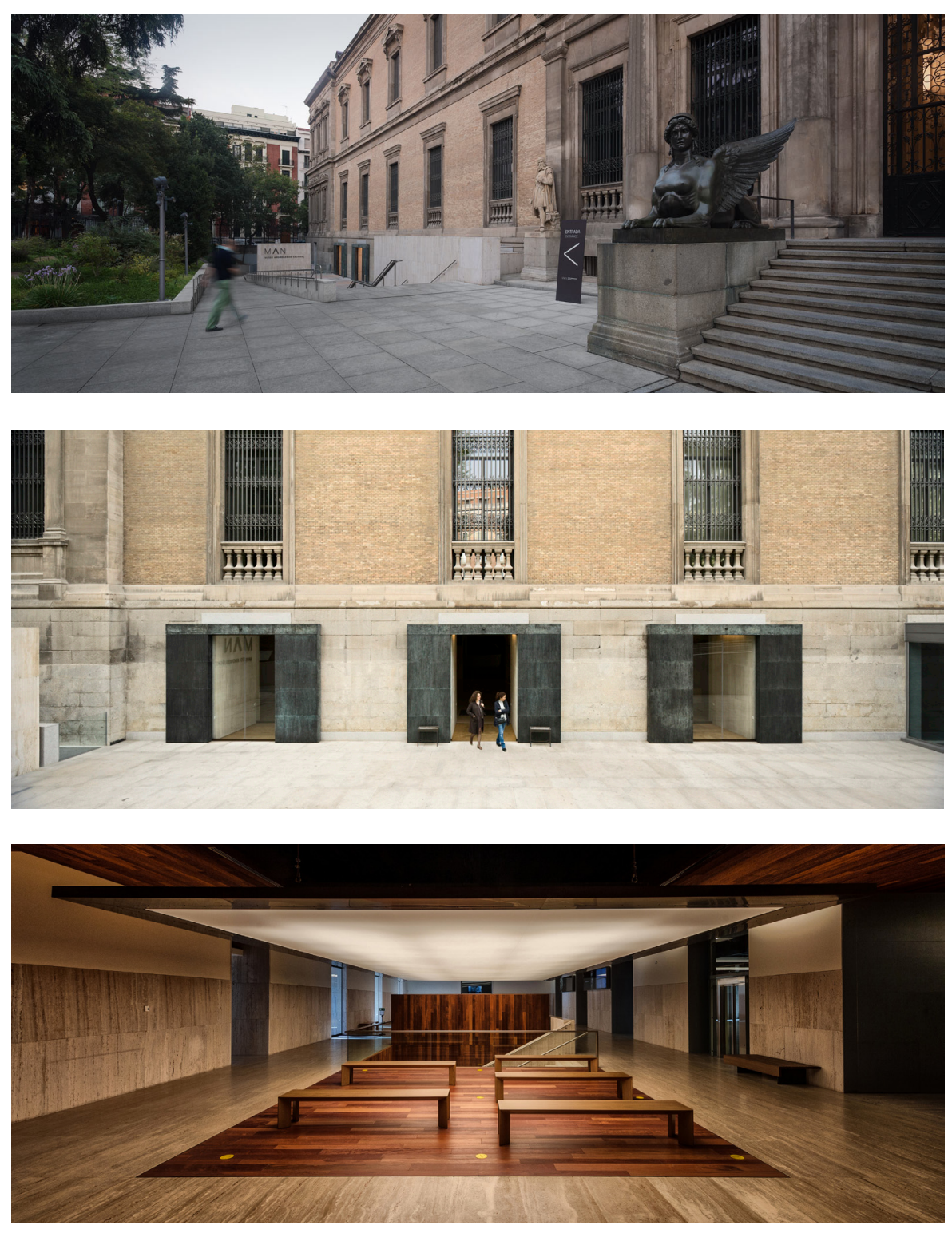

Nuevo acceso | fotos Gabriel López

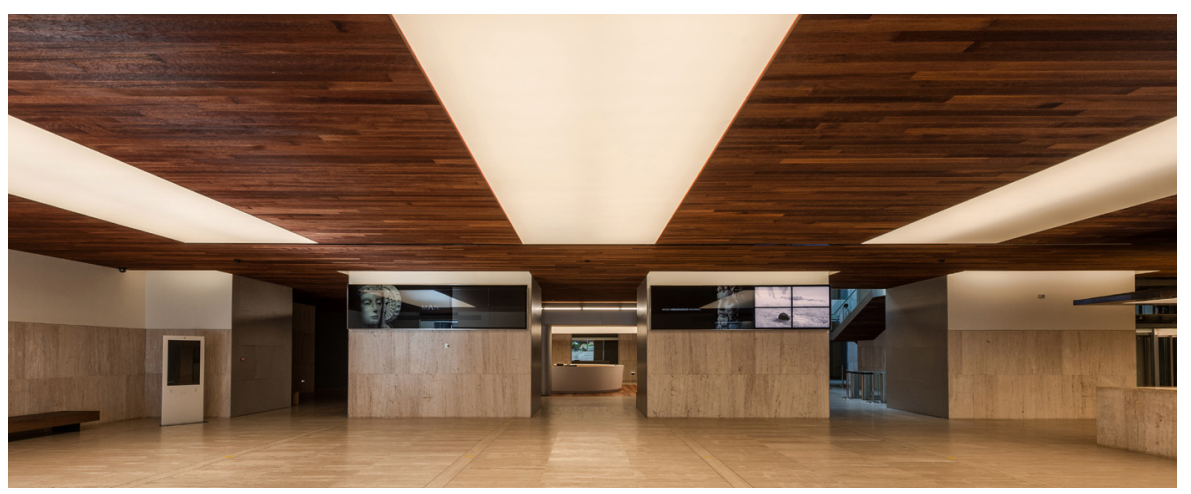

Espacio de acogida de visitantes | fotos Niccoló Guasti 

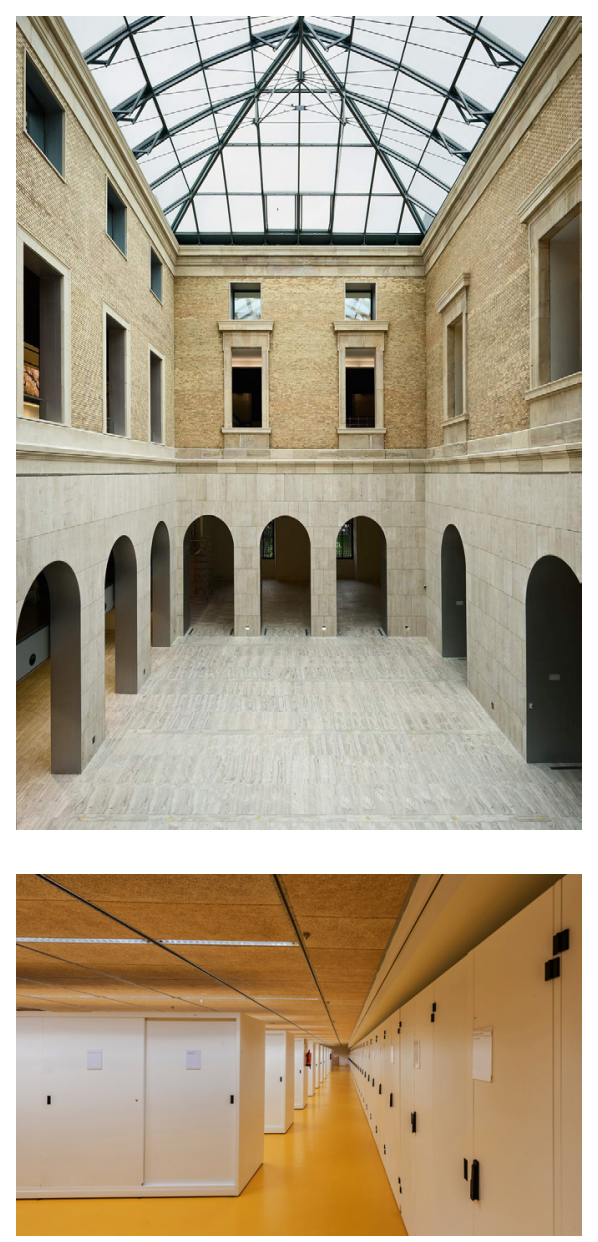

Recuperación de la tipología de patio cubierto con la escalera de nueva construcción | fotos Gabriel López

Almacenes | foto Niccoló Guasti

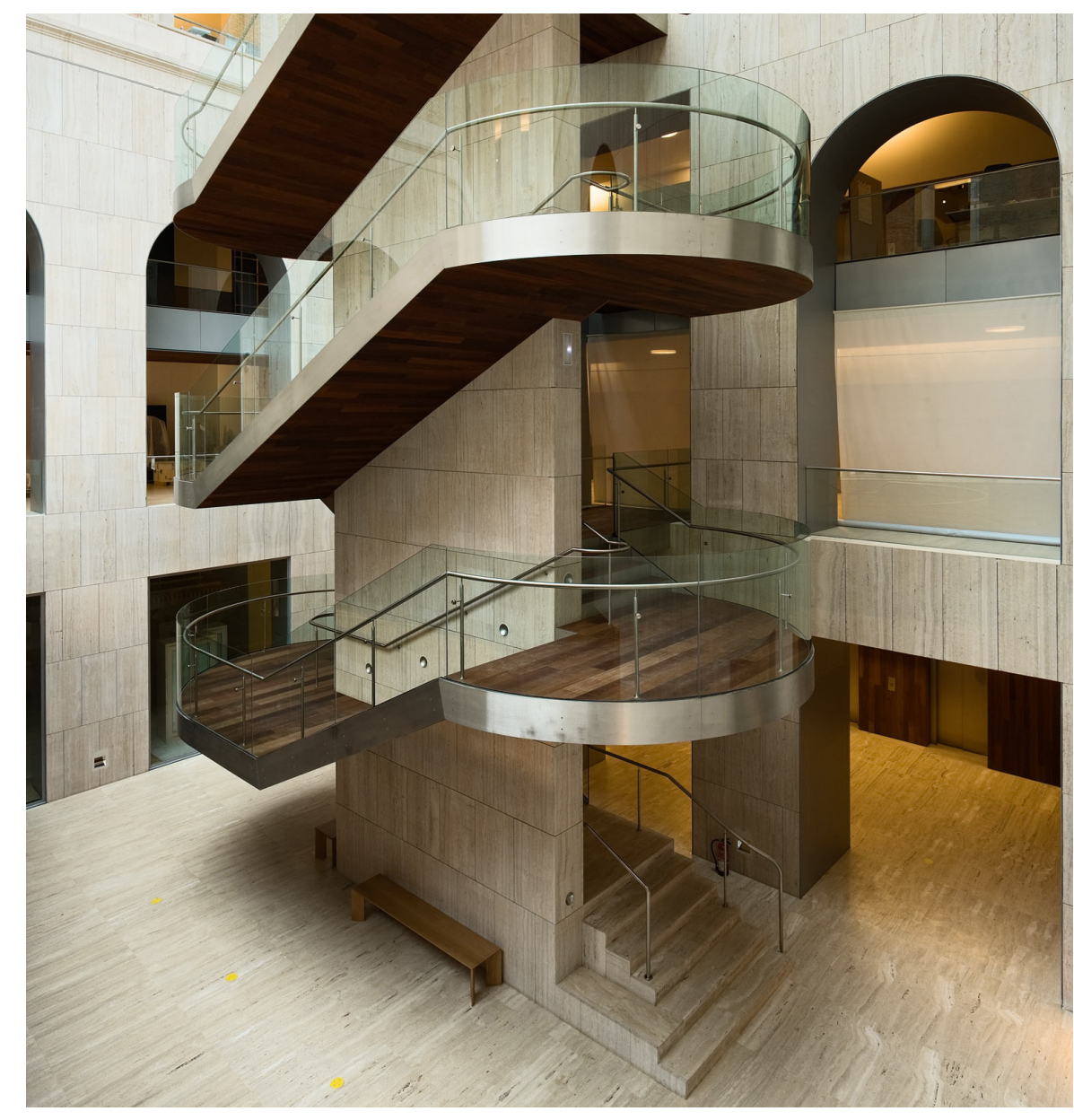

consiguiendo de esta forma devolver la proporción de los patios y aumentar la superficie expositiva con un espacio en doble altura que permite iluminar cenitalmente, mediante una montera ligera de vidrio, la planta baja con luz natural, y que sirve de constante referencia en los recorridos del museo, como de hecho sucedía en la situación original del mismo durante primera mitad del siglo XX. Se recupera por tanto la tipología de edificio que discurre alrededor de patios cubiertos.

Es en este lugar donde aparecen sendas escaleras de gran presencia, tratadas como elementos arquitectónicos de especial relevancia y fundamentales en el recorrido del nuevo MAN, recuperando el valor simbólico de la "escalera" como elemento característico en la arquitectura de museos, pues pasa a ser no solo un elemento que permite el acceso a otros niveles, sino que se erige como auténtica sala del museo desde donde poder disfrutar de la contemplación de los nuevos espacios y de las piezas que alberga. 
Al liberarse la planta segunda de los usos de biblioteca y exposiciones temporales, las dos plantas principales del edificio pueden ahora destinarse en su totalidad para exposición permanente de visita pública alrededor de los dos patios cubiertos. En la planta semisótano se distribuyen las salas de exposiciones temporales, auditorio y sala de conferencias, que pueden funcionar de forma y horario independiente del resto del museo.

Las circulaciones son ahora más claras y flexibles de acuerdo al programa de contenidos y el discurso del museo, pues aparte de ordenar espacialmente el edificio, se han separado los usos de carácter público de los internos. Así, con el planteamiento expuesto, la estructura del edificio permite un enorme grado de flexibilidad en las circulaciones, siendo posible desarrollar recorridos por la parte histórica del conjunto, que pueden resultar enormemente enriquecedores en la visita global al museo, integrando la escalinata y las salas nobles en el recorrido público.

Pretendemos que la intervención no resulte ajena a la historia del edificio, pero somos muy conscientes de la capacidad de los recursos arquitectónicos contemporáneos para potenciar, a veces desde el diálogo y a veces desde el contraste, el auténtico espíritu que se esconde tras las trazas originales. En la obra se respetan muchas de las intervenciones realizadas en los años 70, como son la crujía en el patio medianera con la Biblioteca Nacional, y la planta de almacenes y despachos.

Dado que el Museo Arqueológico Nacional fue uno de los primeros edificios de Madrid con estructura metálica, y con el objeto de habilitar el espacio bajo cubierta como nueva biblioteca, se respetan las cerchas existentes, manteniendo su capacidad portante, y se adecua el espacio al nuevo uso, respetando los elementos estructurales y generando un espacio con lucernario en cumbrera de gran luminosidad.

\section{LAS OBRAS}

Es importante señalar que dada la envergadura de la intervención ha sido preciso ordenar en fases las actuaciones que se acometen con el fin de permitir que el museo permaneciera en todo momento abierto, cumpliendo sus funciones básicas: investigar, conservar y exponer, sin que la institución perdiera su presencia pública, para lo cual se planteó desde un principio la presentación de una selección de las piezas más significativas del museo en la exposición Tesoros del MAN en aquella zona que no se encontraba en obras.

La posibilidad de contemplar una selección de piezas tan relevantes como la Dama de Elche o el Tesoro de Guarrazar en una exposición temporal con un recorrido propio representaba para el museo la oportunidad no sólo de man- 

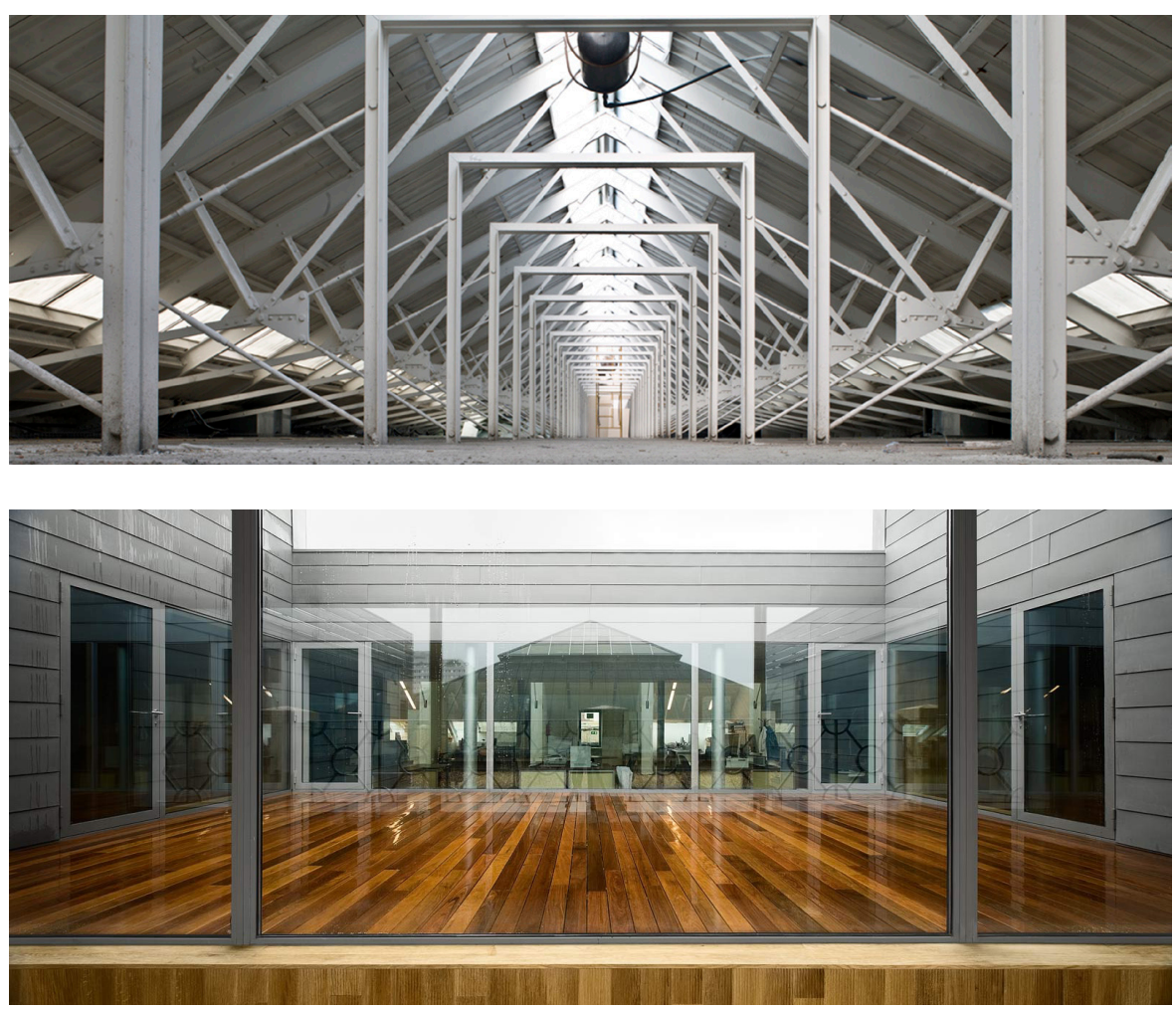

Recuperación de espacio bajo cubierta con las cerchas originales del s. XIX | foto José Manuel Ballester

Patio de la zona administrativa y biblioteca | foto Gabriel López

tener al público fiel, sino también de acercar al visitante no avezado, para quien el imponente número de piezas que alberga el museo pudiera resultar abrumador, a lo que iba a ser el nuevo MAN.

Cabe añadir como motivo de reflexión que la exposición temporal de alrededor de 300 piezas repartidas en cerca de $700 \mathrm{~m}^{2}$ recibió prácticamente el mismo número de visitantes diarios que el museo abierto en su totalidad en los meses previos al comienzo de las obras.

Así, al ser el edifico prácticamente simétrico, en primer lugar se acometieron las obras en el ala norte, exhibiéndose Tesoros del MAN en el ala sur y, una vez terminadas esas obras, se invirtió el planteamiento, para finalizar por último con la restauración de la almendra central del edificio. Las obras duraron cuatro años, de los cuales solo fue necesario cerrar el museo en su totalidad durante un año y medio.

\section{LA MUSEOGRAFÍA}

Durante el transcurso de las obras el Ministerio de Educación Cultura y Deporte convocó un nuevo concurso de Proyecto+Ejecución para desarrollar y ejecutar 

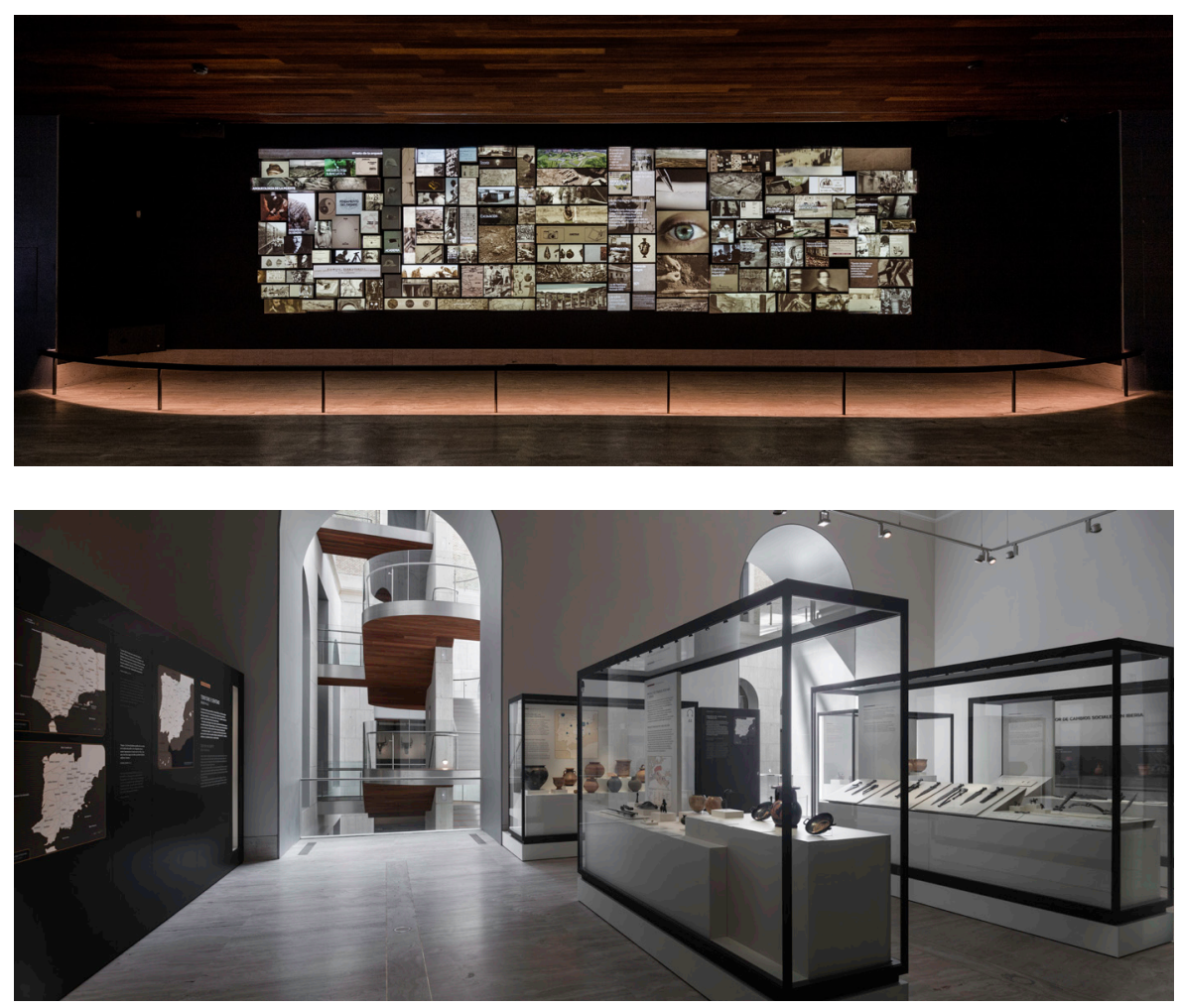

la museografía del nuevo MAN al que Frade Arquitectos concurrió junto con la UTE Acciona Infraestructuras S. A.-Empty, y en el que resultamos adjudicatarios, lo que nos dio la oportunidad de poder continuar con el desarrollo del proyecto como si de un acercamiento focal se tratara, para albergar las piezas en base a un discurso de contenidos desarrollado por los responsables de las colecciones, y constituir su "cara vista" en relación inmediata con el público.

La museografía puede entenderse como la disciplina que establece los cauces de relación entre el edificio, el público y las colecciones, de forma que la visita sea plena en cuanto a los objetivos planteados en el discurso de contenidos.

En este caso estamos hablando de un museo que custodia 1.200.000 piezas de las que se expone cerca de un 1\%; esto es 13.000 objetos, una superficie de exposición de $10.000 \mathrm{~m}^{2}$, y una longitud de recorrido de $3 \mathrm{~km}$.

Se trata de un museo con colecciones muy variadas pues sus contenidos abarcan desde la Prehistoria hasta la Edad Moderna, por lo que puede entenderse como un museo de historia en cuanto al discurso presentado y a la tipología de sus colecciones.
Mapping de introducción a la Arqueología | foto Niccoló Guasti

Sala de Arte ibérico | foto Gabriel López 
1

DOSSIER de prensa. Museo Arqueológico Nacional. Un museo totalmente renovado. 27 de marzo de 2013. Ministerio de Educación Cultura y Deporte, 2013, p. 15 [En línea] $<$ http://www.man.es/man/dms/man/museo/ prensa/notas-de-prensa/2014-03-27-Ruedaprensa/MAN-Dossier-prensa.pdf> (Consulta: $1 / 3 / 2015)$

2

Ibíd., p. 16
El discurso se estructura en tres áreas temáticas:

\section{Área temática 1: arqueología y patrimonio}

"Al inicio del recorrido, novedosa por su planteamiento conceptual y museográfico, se concibe como una presentación multimedia de las principales materias de la exposición. Proyecta una introducción gráfica al mundo de la disciplina y el patrimonio arqueológico (su método de trabajo, tendencias, objetos de investigación, concepto colectivo, bien común compartido), así como los principales temas y soportes materiales que se presentan en las salas a continuación del recorrido. Se complementa con un cronograma cultural de referencia, una presentación multimedia de los principales yacimientos arqueológicos españoles, desde los orígenes de la hominización hasta la fecha de inauguración del MAN, así como un completo recurso interactivo sobre los proyectos arqueológicos desarrollados por investigadores españoles en el exterior"1.

\section{Área temática 2: España como lugar de encuentros}

"Eje principal y vertebrador de la exposición permanente, narra desde los orígenes de la humanidad hasta el siglo XIX, con una presentación de las colecciones del museo, complementada con sugerentes recursos museográficos de apoyo (ilustraciones, maquetas, producciones audiovisuales, elementos interactivos y puntuales escenografías). Propone un recorrido cronológico por las diversas culturas que se han desarrollado en la Península Ibérica y los territorios insulares a partir de su cultura material, mostrando la diversidad cultural, sus continuidades y transformaciones. Contiene distintos módulos temáticos:

$>$ El universo paleolítico.

$>$ Paisajes y sociedades de la Prehistoria Reciente.

$>$ Las novedades del nuevo milenio.

$>$ La formación de los pueblos prerromanos.

$>$ Iberia, un mosaico cultural.

$>$ Hispania Romana.

$>$ De la Antigüedad tardía a la Edad Media.

$>$ Mundo medieval

$>$ Edad Moderna"2.

\section{Área temática 3: de gabinete a museo}

"Narra la historia del museo y el proceso de formación y acrecentamiento de sus colecciones mediante distintos procedimientos, como las misiones arqueológicas o la compra de bienes culturales por parte del Estado, dando lugar a las actuales colecciones externas a la Península Ibérica tales como las del valle del Nilo (Egipto y Nubia), Oriente Próximo Antiguo, Grecia o 

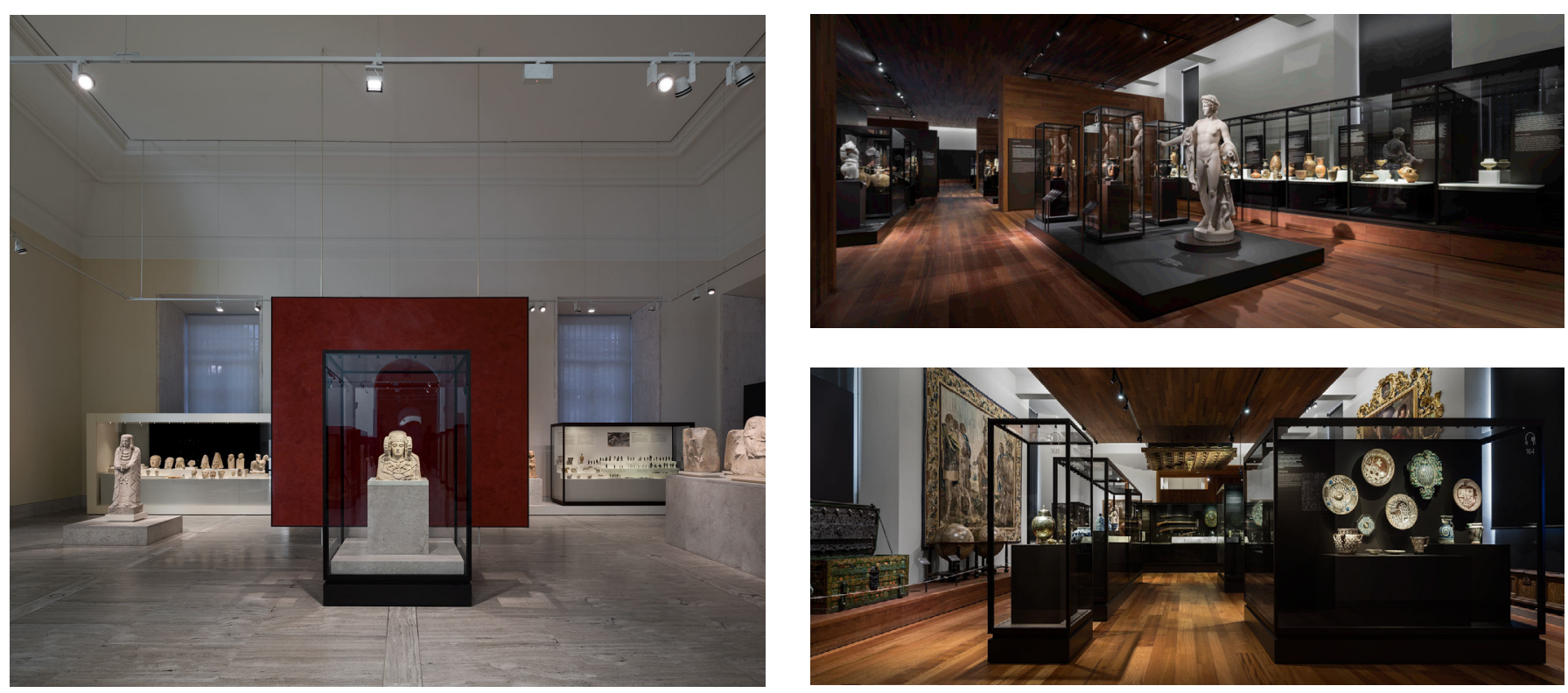

Dama de Elche

Salas de Grecia

numismática y medallística del museo. Contiene, concretamente, los siguientes módulos temáticos:

Salas de la Edad Moderna

| fotos Gabriel López

$>$ Donde habita nuestro pasado.

$>$ Oriente Próximo Antiguo.

$>$ El Nilo: Egipto y Nubia.

$>$ Grecia.

$>$ La moneda, algo más que dinero"3.

3

El edificio sugiere per se el orden cronológico de la visita comenzando con la Prehistoria en planta baja; ascendiendo hacia la planta primera en donde se expone: protohistoria, Roma, Edad Media; y en planta segunda el mundo medieval cristiano y la Edad Moderna con lo que se completa el área "España como lugar de encuentros". En esta misma planta se presenta "De Gabinete a Museo" con aquellas colecciones que, aun siendo muy relevantes en el museo, no se incluyen en la historia de España.

En la entreplanta ubicada entre los pisos $1 .^{\circ}$ y $2 .^{\circ}$ se expone la colección de numismática "La moneda, algo más que dinero". En los patios se exponen las colecciones formadas por piezas de gran formato no fotodegradables $y$ cuya visión aporta interés desde diferentes ángulos y perspectivas en las escaleras de nueva factura.

Así como el Movimiento Moderno nos enseñó que la "forma deriva de la función", en rehabilitación y en museografía creemos que se invierte el postulado, concluyéndose que la "función debe derivarse de la forma"; esto es, resulta necesario entender el edificio y los espacios que lo conforman para 


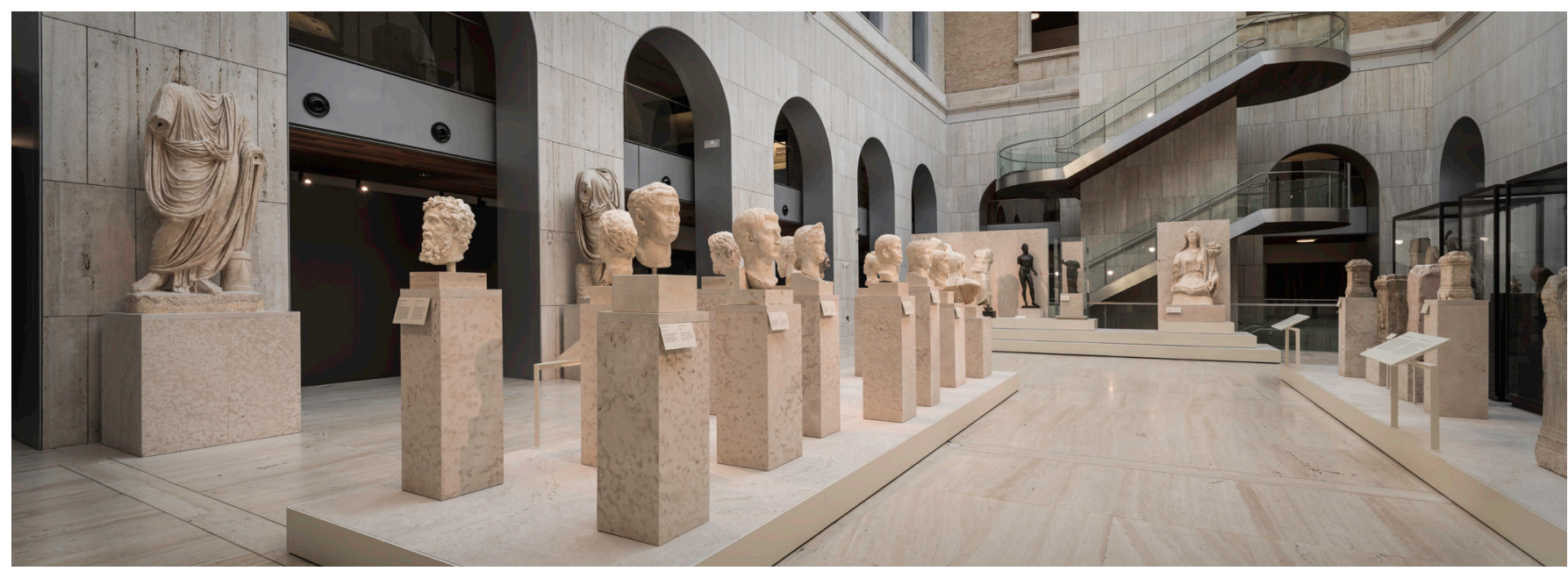

Patio sur | foto Gabriel López

destinarlos a aquellos usos que le son más apropiados, resultando de ello una respuesta natural a la relación entre el edificio y las colecciones.

Tres principios fundamentales han regido la concepción del proyecto museográfico:

\section{Integración entre arquitectura y colecciones}

Atendiendo a las características particulares del museo y dado que el "Palacio de Bibliotecas y Museos" ha sido la sede de la colección desde 1895 y fue creado específicamente para tal fin (una particularidad no muy habitual en los museos españoles), entendemos que el edificio es tan representativo de la institución como la propia colección que alberga, considerando conveniente crear una museografía que dialogue estrechamente con el edificio.

Nuestro objetivo es conformar un museo luminoso, que provoque en el espectador una sensación tranquila y silenciosa, tanto desde un punto de vista formal como conceptual, a través de una museografía que debe tratarse como una prolongación de la remodelación arquitectónica. Un museo en donde la presencia de los patios es constante como espacio de referencia con carácter de lugar de encuentro.

La museografía en este caso debe estar al servicio de las colecciones sin enmascarar el edificio que las aloja. No se trata de negar el edificio, sino de valorar su arquitectura en relación con lo que expone. El éxito de la museografía radica en la adecuación entre colecciones y edificio sin sacrificar los aspectos positivos de ninguno de ellos, potenciando de manera mutua los valores del contenedor y de su contenido. 


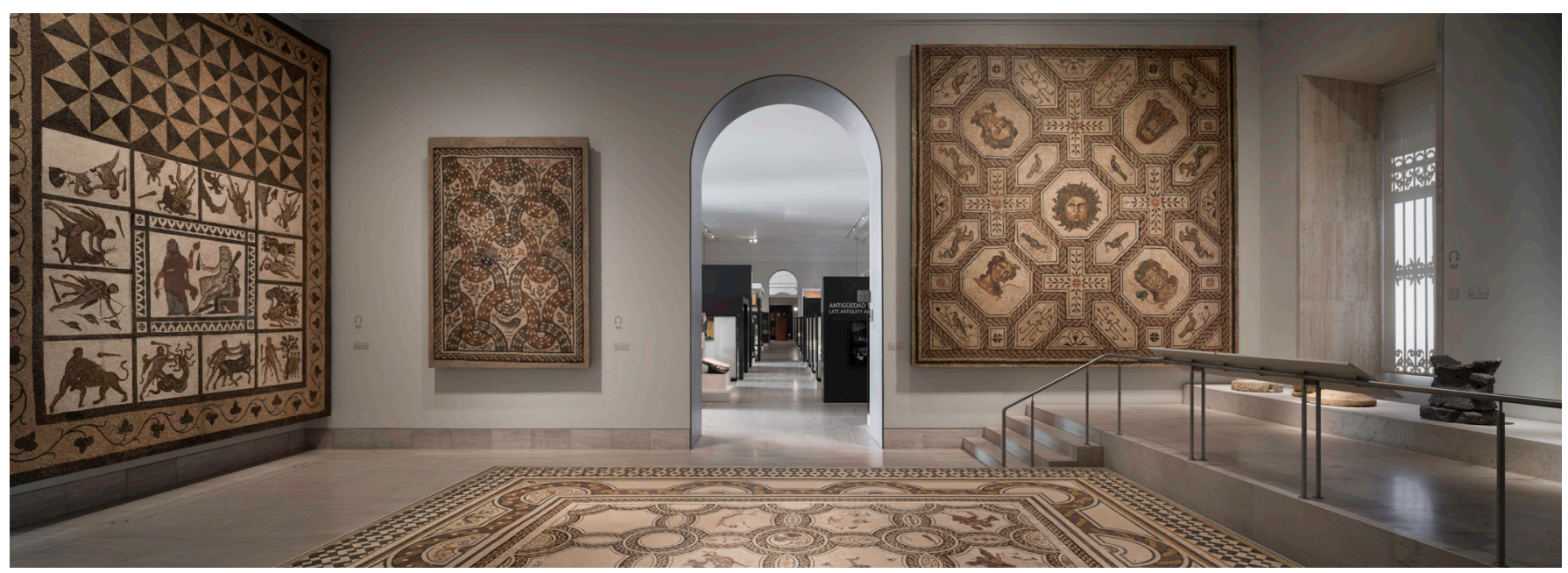

Sala de mosaicos romanos | foto Gabriel López

\section{Museo intemporal}

Al igual que la museografía ideada por Almagro en los años 70 ha resultado vigente durante los últimos cuarenta años, la instalación del nuevo MAN debe resultar atractiva durante las próximas tres o cuatro décadas, y para ello no es necesario ni conveniente una museografía estridente ni ruidosa. Consideramos más interesante realizar un guiño a su pasado, y solapar la emoción que nos transmiten los museos de principios de siglo con la eficacia comunicativa y los requerimientos de conservación que permite la tecnología actual.

Puesto que lo más relevante del MAN son las piezas que alberga, la museografía debe estar al servicio de éstas en relación con el discurso expositivo, compaginando los aspectos contemplativos con los interpretativos. Apostamos, por tanto, por una museografía de diseño sobrio que emociona y sugiere sin aspavientos innecesarios. No debe tratarse como un museo "de usar y tirar", por lo que hemos elegido una familia de expositores neutros que valoran la pieza, respetan el edificio, y ofrecen las prestaciones necesarias sin hacer un homenaje a la tecnología que ocultan. El museo no debe girar en torno a los recursos tecnológicos. Los nuevos sistemas deben utilizarse como medio para alcanzar los objetivos fijados y no como fin en sí mismos, por lo que, aun sirviéndose de ellos, se despliegan en recintos puntuales para no entorpecer la visión de las piezas ni reducir la presencia del edificio.

Entendemos que tanto los materiales utilizados: piedra de travertino, palastros metálicos, vidrio, madera de merbau, etc., como el lenguaje usado, aportan calidez a la instalación en donde el paso del tiempo debe potenciar su calidad material, de manera que su intemporalidad se manifestará a través del digno envejecimiento de sus acabados. 


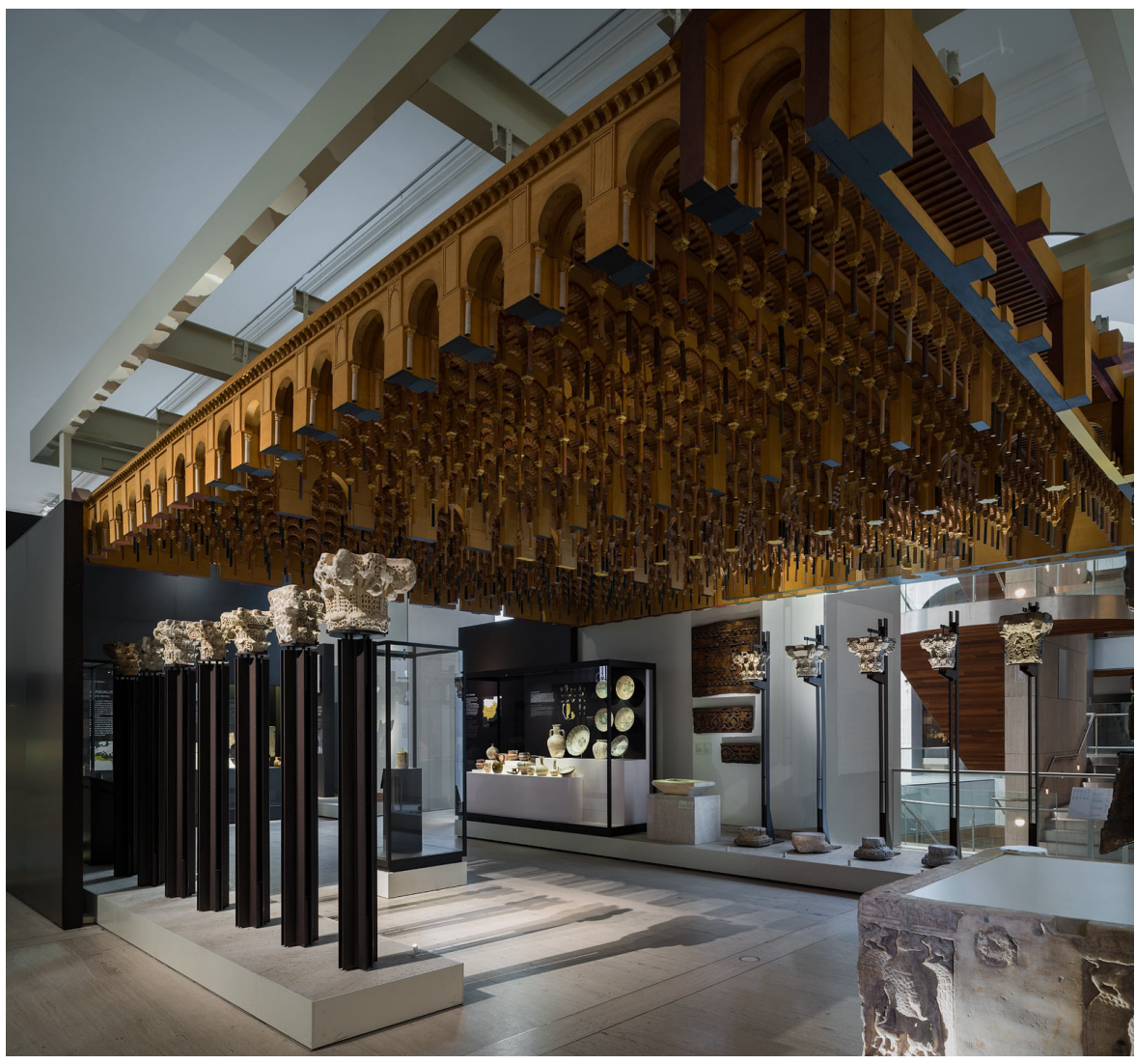

Maqueta de la Mezquita de Córdoba sobre la sala de al-Ándalus | foto Gabriel López

\section{Planteamiento flexible}

En lo esencial, el modelo de exposición será el mismo en todo el museo. Aun cuando no creemos aconsejable en este caso diseñar formalizaciones muy diferenciadas entre las distintas secciones pues se corre el riesgo de fragmentar un discurso unitario con modelos escenográficos propios de las exposiciones temporales, sí se utilizan diferentes recursos sobre un mismo esquema director.

En cuanto a los elementos museográficos, también se opta por una única familia de recursos para todo el museo, presentando estos elementos un diseño muy estudiado tanto en sí mismos como en sus relaciones pues, dependiendo de los intereses del discurso expositivo, las vitrinas, peanas, soportes y resto de recursos, deberán combinarse formalizando, desde una estructura pautada, gestos diversos que personalicen cada área.

La posibilidad de intercambiar la ubicación de las piezas y de los elementos museográficos de un espacio a otro sin demasiada dificultad es hoy una necesidad en el campo de la museografía, en donde el estudio de las colecciones o las nuevas adquisiciones pueden hacer que el discurso o las nece- 
sidades del museo varíen. La museografía debe ser flexible, pues estará supeditada a la rotación y el análisis de nuevos contextos e interpretaciones de las colecciones.

Los condicionantes museográficos del nuevo Museo Arqueológico Nacional son interminables. De una parte, el edificio, con una zona central histórica medianera con la Biblioteca Nacional, dos patios cubiertos, grandes ventanales a ambos lados de las crujías, y con una arquitectura de rasgos muy potentes cuyo impacto es necesario dosificar de forma adecuada para fomentar el disfrute de las piezas. De la otra, las piezas que conforman un discurso concreto y, por tanto, responden con un lugar prefijado en la exposición, y que se relacionan entre sí para elaborar un guión dentro de ese discurso. Al mismo tiempo, cada pieza tiene también unas dimensiones concretas y un peso específico que condiciona su situación sobre según qué lugar de la estructura del edificio. En cierto modo, algunas de las piezas demandan un espacio determinado que no debe obviarse en el proyecto de contenidos.

Del cruce de la totalidad de los datos disponibles acaba surgiendo una posibilidad que los engloba y que es válida conceptualmente, esto es: una distribución que cumple con un carácter eminentemente cronológico e interpretativo del programa de contenidos, pero que no olvida la profunda emoción que nos transmiten las piezas de cada una de las áreas y secciones que se presentan en el Museo Arqueológico Nacional.

\section{CONCLUSIONES}

Como motivo de reflexión resulta interesante subrayar dos datos:

> El museo recibía antes de las obras realizadas del orden de 100.000 visitantes cada seis meses. En los siete primeros meses contabilizados, hasta diciembre de 2014, ha recibido 700.000 visitantes.

> La inversión para las obras ha sido de 32 millones de euros, que repartidos en los $30.000 \mathrm{~m}^{2}$ remodelados, supone un ratio de 1.066 euros $/ \mathrm{m}^{2}$. Incluyendo el coste de la instalación museográfica y equipamiento de sus espacios, el ratio resulta de $2.100,00$ euros $/ \mathrm{m}^{2}$.

Nota redacción

Juan Pablo Rodríguez Frade es Premio Nacional 1995 de Restauración y Rehabilitación de Bienes Culturales por la Rehabilitación del Palacio de Carlos V como Museo de la Alhambra. 